\title{
Red Cell Aging in Vivo
}

\author{
A. M. Ganzoni, R. Oakes, and R. S. Hillman \\ From the Medical Policlinic of the University of Zurich, 8006 Zurich, \\ Switzerland, and the Department of Medicine, University of Washington, \\ School of Medicine, Seattle, Washington 98105
}

\begin{abstract}
A B S T RACT Previous studies of red cell structure and metabolism during the aging process have relied upon in vitro techniques of cell separation into various age populations. Probably the most common approach is to isolate the older red cells with the assumption that they are more dense. This may lead to a number of inconsistencies in observations, and may certainly raise questions about possible cell changes secondary to manipulative procedures. For this reason, an experimental system was devised where a normal red cell population could be studied, while aging, in an in vivo environment. The initial red cell mass of a large number of inbred rats was transferred repeatedly into an ever smaller number of animals, making it possible to follow an aging population of red cells up to 48 days while preventing contamination with newly produced cells by suppression of erythropoiesis with transfusion-induced polycythemia. During this period, samples of progressively older red cells could be obtained for measurements of red cell constant. It was noted that the normal rat red cell undergoes both volume reduction and significant hemoglobin content loss with aging. In addition, the hemoglobin concentration within the cell demonstrated an early rise after a return to nearly normal values. These findings are noteworthy in that they help to explain the characteristics of life-spans of cohort labeled red cell populations in small animals, and provide a possible example of a cell's remodeling process within the spleen.
\end{abstract}

\section{INTRODUCTION}

A number of investigators have attempted to describe the morphologic and metabolic changes which erythrocytes undergo during the aging process (1-18). For such studies, a method for separating red cell populations according to age is required. Several techniques have been employed including separation by differential

Received for publication 28 April 1970 and in revised form 18 February 1971. agglutination $(14,15)$, osmotic fragility $(16)$, induction of anemia (13), marrow damage by irradiation (17) or drug administration (19), and transfusion of red cells into patients with aregenerative anemia (18). The most common methods used, however, have been a variety of centrifugation techniques (1-11). This approach not only assumes that older red cells are more dense but also that they are not altered significantly by the in vitro separation procedure. Naturally, these assumptions would be of less concern if consistent and reproducible data were forthcoming from these methods. However, even in respect to measurements of cell size and hemoglobin content, there has been little agreement among investigators. For example, in recent studies, a reduction $(10,17)$, increase (8), and constancy (11) of mean corpuscular volume have been recorded.

In view of these conflicting results, an effort was made to devise an experimental system which permits the study of aging red cell populations in an in vivo environment. Although other investigators have made attempts to study cells in vivo $(13,17-19)$, this is, to our knowledge, the first description of a model which permits the study of normal red cells during more than $80 \%$ of their life-span while circulating in a healthy animal. By applying the previously described technique of transfusion-induced erythroid marrow depression (20), a normal red cell population was observed in rats for a period of 43-48 days without significant contamination by newly produced cells. It was apparent that the aging red cell undergoes both a volume reduction and significant hemoglobin loss-changes which have previously been described only in anemia induced macrocytes (20).

\section{METHODS}

Experimental model. In two separate experiments, 120 150 highly inbred rats were initially divided into donor, recipient, and control groups (Fig. 1). Study $A$, performed in Zurich, Switzerland, used female Osborn-Mendel rats, weighing $250-300 \mathrm{~g}$, and study $B$, performed in Seattle, Washington, used male Simonson Albino rats, weighing 


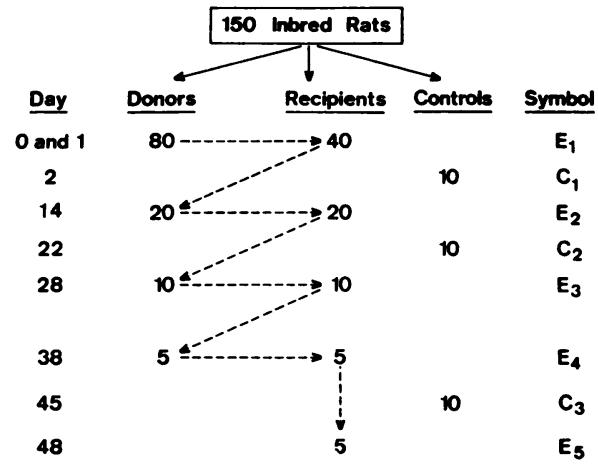

Figure 1. Study A. Experimental model for concentration of a progressively older population of normal rat red cells in an ever smaller number of animals. Red cell measurements were performed on study rats at points $E_{1}$ to $E_{5}$; control rats were chosen at random from the initial group and studied at points $C_{1}$ to $C_{3}$. Study $B$ differed only slightly in terms of the timing of recipient transfusions: $E_{2}, 15$ th day; $E_{:}, 27$ th day; $E_{4}$, 36th day; and $E_{5}$, 43rd day.

$350-4 \mathrm{C} 0 \mathrm{~g}$. On day 0 and 1,40 recipient animals were hypertransfused (65-75\% hematocrit values) by tail vein injections (9-12 $\mathrm{ml}$ ) of pooled heparinized whole blood obtained by cardiac puncture from 80 or more donor animals. The length of time the cells spent outside the circulation was kept below $30 \mathrm{~min}$. Subsequently, the hematocrit value of the hypertransfused recipients remained above $50 \%$ for the next 14 days. At this time, half the group was used as donors to maintain the hypertransfused state in the remaining 20 rats. This procedure was repeated in study $A$ on days 28 and 38 until five animals were left $\left(E_{1}-E_{5}\right.$, Fig. 1). On day 48 of study $A$, and day 43 of study $B$, the experiment was terminated when the last five animals were sacrificed for determination of their red cell life-spans. 30 rats selected at random from the initial animals were employed as controls. They were sacrificed in groups of 10 on days 2,22 , and $45\left(C_{1}-C_{3}, F i g .1\right)$ for cell constant measurements and life-span determinations.

Normal red cell measurements. At the time of each hypertransfusion $\left(E_{1}-E_{5}\right)$, donor blood from each of 5 to 10 animals was used to determine both the mean cell constant and the volume frequency distribution of the circulating red cells. All measurements were performed in triplicate. Hematocrits were determined by the microhematocrit method; hemoglobins were assayed by the cyanmethemoglobin technique. Red cell counts were performed on either a Model F or Model B Coulter counter (Coulter Electronics, Inc., Hialeah, Fla.) using isoton as diluent. Red cell volume distribution plots (study $A$ ) were determined on the Model $B$ Coulter counter, equipped with a $100 \mu$ aperture tube, and the Model $J$ size distribution plotter (11, 21-23). For sizing, the cell concentration was adjusted to approximately $10,000 / \mathrm{ml}$, the aperture current switch set at $\frac{1}{2}(1 \mathrm{ma})$, and the amplification at $\frac{1}{8}$. Five plots were registered using separate dilutions of each sample studied, and an average volume distribution was calculated. In study $A$, hematocrits and mean corpuscular volumes $(\mathrm{MCV})^{1}$ were also measured with the corresponding Coulter computers.

${ }^{1}$ Abbreviations used in this paper: ACD, acid citrate dextrose solution; $\mathrm{MCH}$, mean corpuscular hemoglobin; $\mathrm{MCHC}$, mean corpuscular hemoglobin concentration; MCV, mean corpuscular volume.
There was good agreement between the measurements obtained by the conventional methods and the Coulter instruments over the full range studied (hematocrit, $r=0.97$; MCV, $r=0.83$ ). Consequently, average values were used. Both the accuracy of these measurements, when performed repeatedly on a single sample, and the constancy of the control animals' values during the 7 wk of the study are summarized in Table I. Suppression of red cell production by hypertransfusion has been documented using reticulocyte counts and radioiron incorporation (20). In these studies, continued suppression of red cell production was monitored with repeated reticulocyte counts. After supravital staining with new methylene blue, the number of reticulocytes among $50 \mathrm{C0}$ red cells was enumerated using five different coverslips. Whereas the normal control rats demonstrated mean reticulocyte counts of 1.0 to $1.5 \times 10^{5} / \mathrm{mm}^{3}$, the hypertransfused animals maintained an average count of $0.13 \times 10^{5} / \mathrm{mm}^{3}$, ranging from 0.05 to $0.19 \times 10^{5} / \mathrm{mm}^{3}$. Marrow production was thus reduced to less than $10 \%$ of normal. Reticulocyte counts were always recorded on the days of transfusion, when hematocrits were at lowest levels. It would be expected that marrow depression was even greater on the days immediately after hypertransfusion.

The red cell population of each of the remaining hypertransfused rats $\left(E_{5}\right)$, and the control rats sacrificed on day $45\left(\mathrm{C}_{3}\right)$ were labeled with ${ }^{51} \mathrm{Cr}$ and their survival determined in normal and splenectomized recipients $(24,25)$. $1 \mathrm{ml}$ of whole blood from each study animal was incubated with $50 \mathrm{uCi}{ }^{51} \mathrm{Cr}$ in (ACD) acid citrate dextrose solution for $15 \mathrm{~min}$ at room temperature, washed three times with five volumes of rat plasma, and an equal portion injected into the recipients using the tail vein route. Samples were taken from the tail vein at $2 \mathrm{hr}, 2$ days, and at 1-2 day intervals thereafter. $0.02 \mathrm{ml}$ was pipetted into $2 \mathrm{ml}$ distilled water and counted on a Nuclear-Chicago Gamma Well Type Scintillation Counter (Nuclear Corp., N. J.) to 10,000 counts above background for $\pm 1 \%$ accuracy.

\section{RESULTS}

Mean cell constants. The changes in mean cell constants during in vivo aging are summarized in Fig. 2. The MCV fell in a nearly linear fashion with a $13-16 \%$ reduction in volume by the $40-45$ th day. At the same time, the mean corpuscular hemoglobin ( $\mathrm{MCH})$, demonstrated a reduction of $11-13 \%$ of the original hemoglobin content of the cell. There was, however, no change in the $\mathrm{MCH}$ for the first $2 \mathrm{wk}$ in the aging study.

The early fall in MCV did correlate with a rise in mean corpuscular hemoglobin concentration (MCHC). There was a 4-7\% rise in $\mathrm{MCHC}$ during the first 25 days of the study. Interestingly, this increase was not maintained. The MCHC returned towards normal after the 25 day until the value barely exceeded the original and control measurements.

Volume distribution studies. As the cell population aged, the volume frequency distribution curve was significantly shifted towards smaller cell volumes (Fig. 3 ). This phenomenon appeared to involve every cell since the original asymmetry of the curve remained unaltered with the shift to the left. 
TABLE I

Accuracy of Red Cell Measurements

\begin{tabular}{lccc}
\hline & Red cell count & Hemoglobin & Hematocrit \\
\hline & $\times 10^{8 / m^{3}}$ & $g / 100 \mathrm{ml}$ & $\%$ \\
Repeated determinations on a single sample (mean $\pm 1 \mathrm{SE})\left(\mathrm{n}^{*}, 15\right)$ & $7.03 \pm 0.09$ & $13.2 \pm 0.21$ & $43.1 \pm 0.08$ \\
$\begin{array}{l}\left.\text { Control animal measurements } \mathrm{C}_{1}, \mathrm{C}_{2} \text {, and } \mathrm{C}_{3}, \mathrm{Fig} .1 \text {, (mean } \pm 1 \mathrm{SD}\right) \\
\left(\mathrm{n}^{*}, 28\right)\end{array}$ & $6.95 \pm 0.43$ & $14.6 \pm 0.7$ & $42.6 \pm 2.4$ \\
\hline
\end{tabular}

* n, number of observations.

Red cell survival studies. The half clearance time $\left(\mathrm{t}_{i}\right)$ of normal rat erythrocytes labeled with ${ }^{51} \mathrm{Cr}$ are summarized in Table II and Fig. 4. The mean ${ }^{51} \mathrm{Cr} \mathrm{t}_{\frac{1}{2}}$ for normal rat red cells injected into normal recipients was 14.5 days for study $A$, and 18.5 days for study $B$. When cells were injected into splenectomized recipients in study $A$, the mean ${ }^{51} \mathrm{Cr}$ t 13 was 19.5 days. Meanwhile, the recovered red cells from the hypertransfused rats sacri-
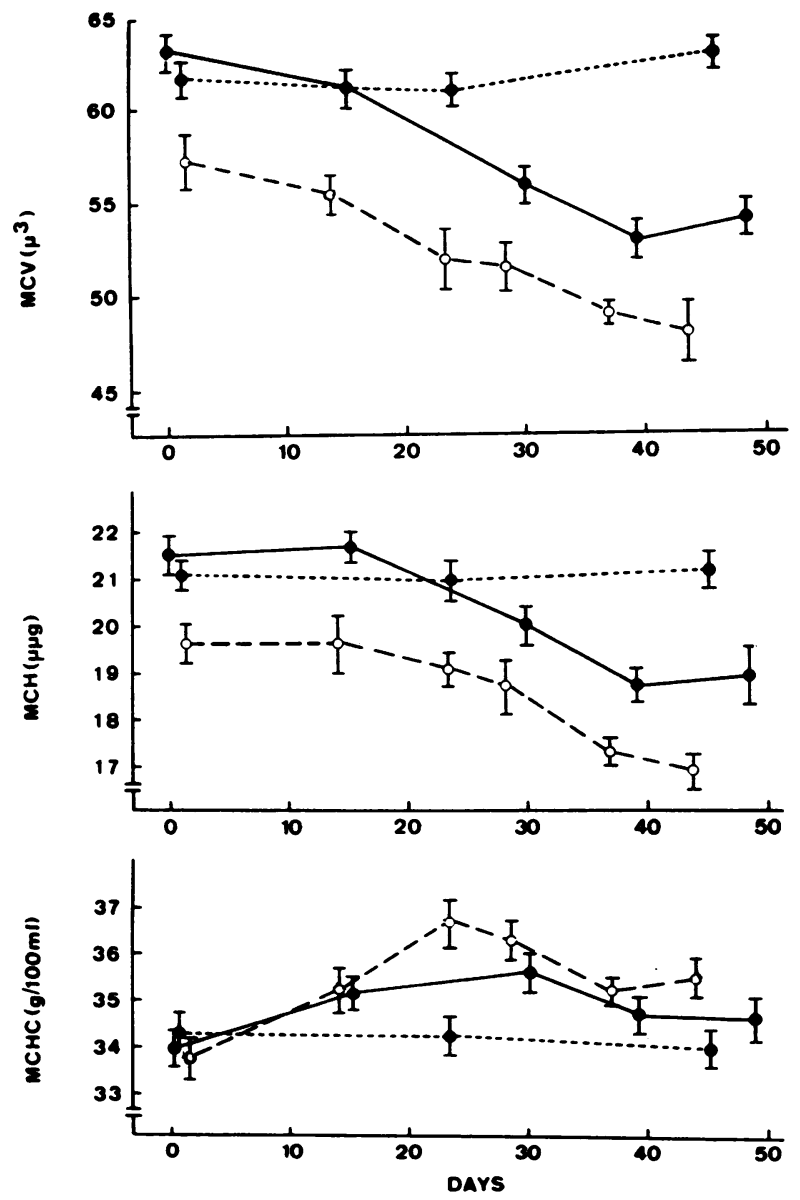

FIGURE 2 Changes in red cell constants (mean $\pm 1 \mathrm{SE}$ ) over the 43 to 48 day study period. Control animals-solid dots, broken line; study A-solid dots, solid line; study B-open circles, broken line. It will be noted that the animals used in study $B$ had cells of smaller sizes. ficed on day 48 (study $A$ ), had a ${ }^{51} \mathrm{Cr}$ t of 4.5 days in normal recipients, and 8.2 days in splenectomized recipients. The cells recovered on day 43 in study $B$ had $a^{51} \mathrm{Cr} \mathrm{t}_{1}$ of 6.2 day in normal recipients. In addition, the ${ }^{51} \mathrm{Cr}$ survival curves of the study $A$ recipients appeared to demonstrate a biphasic disappearance. Beyond day 6 , the rate of elimination was accelerated, fitting exponentials with ti's of 3.2 and 4.8 days for nonsplenectomized and splenectomized recipients respectively.

\section{DISCUSSION}

A study of macrocyte populations released into the circulation of rats stimulated by anemia revealed that the individual macrocyte can lose both cell water and a portion of its hemoglobin while in circulation without impairment of continued viability (20). By this mechanism, macrocytes can attain, essentially, normal MCV, $\mathrm{MCH}$, and $\mathrm{MCHC}$ values within a few days of their release from the erythroid marrow. Normal values were defined as those observed in adult animals of the same strain that had not been bled. Subsequently, these cells appeared to undergo only minor changes in size and composition in the several weeks of their life-span

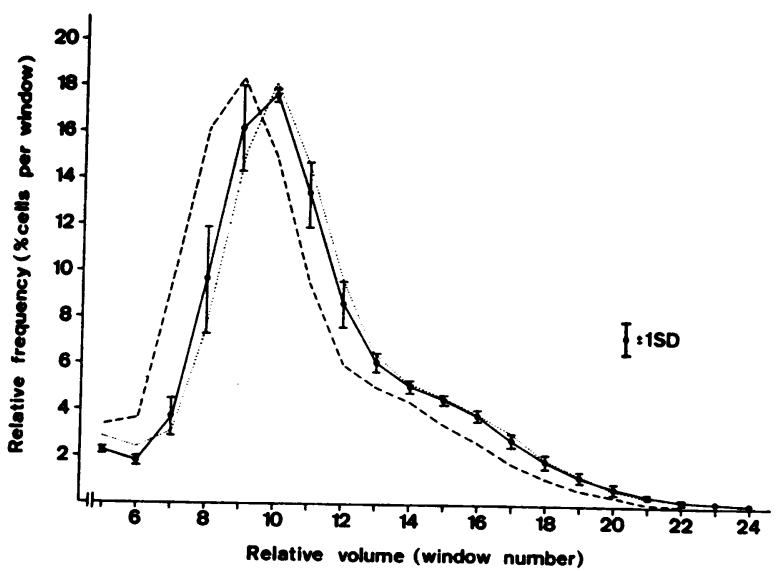

FIGURE 3 Study A. Volume frequency distribution of red cell populations of different age composition. Three patterns are shown: control animals (solid line), pooled blood of five donor animals at day $\mathrm{O}$ (fine dotted line), and blood from the animals sacrificed on day 48 (broken line). 
TABLE II

${ }^{51} \mathrm{Cr}$ Life-span ( $\left.t_{\mathrm{\xi}}\right)$ of Normal and Hypertransfused Recipients at the End of the Study

\begin{tabular}{|c|c|}
\hline & ${ }^{s 1} \mathrm{Cr} \mathrm{t}$ \\
\hline & Mean $\quad$ SE \\
\hline Control rats & days \\
\hline $\begin{array}{l}\text { Study } A, 5^{*} \\
\quad \text { Normal } \\
\text { Splenectomized }\end{array}$ & $\begin{array}{l}14.5 \pm 1.5 \\
19.5 \pm 1.5\end{array}$ \\
\hline $\begin{array}{l}\text { Study } B, 3^{*} \\
\text { Normal }\end{array}$ & $18.5 \pm 1.0$ \\
\hline Hypertransfused rats & \\
\hline $\begin{array}{l}\text { Study } A, 5^{*} \\
\quad \text { Normal } \\
\text { Splenectomized }\end{array}$ & $\begin{array}{l}4.5 \pm 0.5 \\
8.2 \pm 0.6\end{array}$ \\
\hline $\begin{array}{l}\text { Study } B, 4^{*} \\
\text { Normal }\end{array}$ & $6.2 \pm 0.5$ \\
\hline
\end{tabular}

* Number of recipients used in experiment.

(20). However, using albumin density gradients for separation of cohort labeled rabbit red cells, Piomelli, Lurinsky, and Wassermann (10) were able to demonstrate a continuous increase in $\mathrm{MCHC}$ and a fall in $\mathrm{MCV}$ as cells aged. Moreover, a decrease in $\mathrm{MCH}$ with age was reported by Sondhaus (26) more than a decade ago. Using microspectrophotometry, he found significantly smaller amounts of hemoglobin in cells recovered from the bottom of a centrifuge tube in comparison to the younger cells localized in the top section.

In view of our experience with the rat macrocyte, the previously described in vivo technique for the study of red cell maturation was adapted to the study of normal rat red cell populations during the aging process. The circulating red cells of 120-150 highly inbred rats were repeatedly transfused into an ever smaller number of recipients, maintaining their hematocrits above $50 \%$ so as to suppress erythropoiesis and thereby prevent contamination of the original population with newly produced cells. Absence of significant contamination by newly produced cells was confirmed both by repeated measurements of reticulocyte production, and by the performance of ${ }^{\circ 1} \mathrm{Cr}$ life-spans on the cell populations recovered after the 43rd day. Assuming a 60 day lifespan of rat erythrocytes $(24,25)$, the mean red cell age was 30 days at the beginning of the experiment. At days $14,28,38$, and 48 , when specific investigations were carried out (Study $A$ ), the mean age had progressed to $37,44,49$ and 54 days respectively. This model, therefore, permitted repeated observations of cell constants as the original normal age distribution of a relatively large pool of circulating cells shifted to a progressively older and more uniform age population. Moreover, it avoided many of the problems of possible environmental damage and extravascular manipulation that have plagued other studies (1-17).

Using this system, two complete separate studies were performed. In both, erythrocyte aging was associated with distinct changes in the red cell constant. As reported by Piomelli et al. there was a significant fall in the $\mathrm{MCV}$, and an increase in the $\mathrm{MCHC}$ during the first 25 days of the study. It thus appears that volume reduction by cell water loss is experienced both by reticulocytes and the younger portion of the circulating adult red cell population. As shown in Fig. 5, this loss would tend to be most rapid as the reticulocyte enters

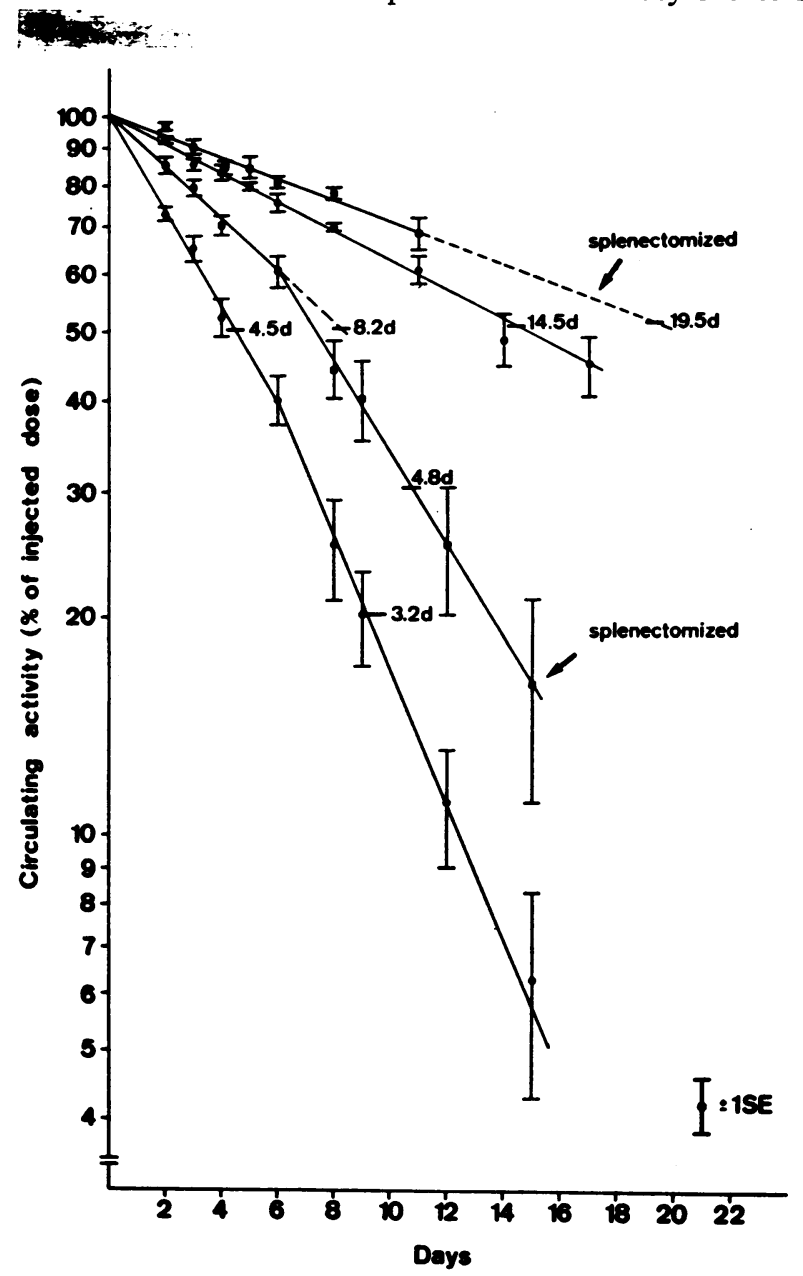

Figure 4 Study A. Survival of ${ }^{51} \mathrm{Cr}$-labeled red cells of control and experimental animals sacrificed at day 48 in normal and splenectomized recipients. The upper two curves were seen with normal cells, the lower curves were typical of the aged cells. A double exponential curve was apparent in the case of the aged cells. The explanation for this finding, and the apparent difference in survival in normal versus splenectomized recipients was not clear. 
circulation and would then gradually taper off during the early part of the circulating red cell's life span.

The oldest cells did not show a continuous rise in MCHC. Instead, late in their life span, the cells demonstrated a steady decrease in their $\mathrm{MCH}$ which was from then on the major cause of a continued decrease in the MCV. From the 25th to the 43rd-47th day, the $\mathrm{MCH}$ fell continuously until $11 \%$ reduction had occurred. At the same time, the $\mathrm{MCHC}$ reversed its upward trend, and began to fall, suggesting that proportionately, more hemoglobin than cell water and electrolyte was being removed from the cells. This observation must raise some doubts about studies which used density gradient techniques to identify older red cells (1-11).

At least two mechanisms of rat red cell shrinkage may be identified. The first, loss of cell water occurs early in the life-span and may well accompany the degradation of ribosomes and ribonucleic acid proteins. Thus, it would be more marked in the reticulocyte stage, and then would gradually decrease during the first weeks of life. In contrast, the second, a loss of hemoglobin of individual red cells can occur at two specific times in the life span of the rat erythrocytes. Anemia-induced macrocytes show as much as $15 \%$ loss of cell hemoglobin within 10 days of their release into circulation (20). This hemoglobin loss is accompanied by a major loss in cell membrane," suggesting a mechanical remodeling of macrocytes without an apparent reduction in viability (28). Such a phenomenon would help to explain the early-labeled bilirubin pigment fraction observed when anemic rats are labeled with the heme precursor glycine-2- ${ }^{14} \mathrm{C}(28)$.

Once the red cell approaches a normal volume, this process seems to cease. Only in the later part of the red cells' life-span does the process of cell hemoglobin loss resume. At this time, a $13 \%$ or better reduction in cell volume and hemoglobin occurs. Theoretically, this apparent remodeling of the red cells could be caused by a loss of a specific population of large cells with increased hemoglobin content; although not directly excluded, this possibility seems unlikely in view of the symmetry of the cell volume distribution curve with aging. The shape of the cell volume pattern on the 48th day was identical with that found in control animals, exhibiting the typical skew toward the right. If larger red cells were being destroyed preferentially, it would seem likely that the minor population of big cells would have disappeared, thereby changing the shape of the right side of the curve.

These findings are of significance in at least two areas. First, they may help to interpret small animal red cell lifespan data. Using cohort labeled populations,

\footnotetext{
${ }^{2}$ Robinson, S. H. Personal communication.
}

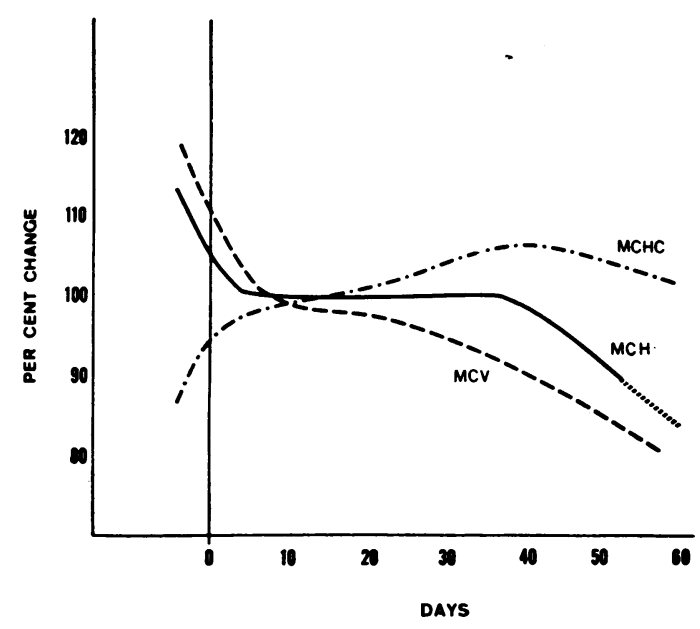

Figure 5. Theoretical plot of the changes in MCV, MCH, and $\mathrm{MCHC}$ during the life-span of a rat red cell. To the left of day $\mathrm{O}$, the marrow reticulocyte, as estimated from studies of anemia induced macroreticulocytes (20), demonstrates a rapid reduction in size and an increase in hemoglobin concentration. The latter continues during the early part of the cells' life-span, perhaps in conjunction with the last degradation of ribonucleic acid and ribosomes. Later cell shrinkage becomes even more rapid as cells lose hemoglobin content. This appears to be associated with a simultaneous fall in MCHC.

a gradual loss of up to $15-20 \%$ of the label is seen in the later half of life-span curves. This has been attributed to a random loss of red cells $(24,25)$. The present study would indicate that this may not be the correct explanation. Rather, the loss of amino acid- ${ }^{14} \mathrm{C}$ or ${ }^{50} \mathrm{Fe}$ activity would be a reflection of the reduction in cell hemoglobin. Secondly, in view of Weed and Reed's work on spleen red cell interaction (27), it is of interest to see a fall in $\mathrm{MCHC}$ accompanying the $\mathrm{MCH}$ reduction. The latter phenomenon could be cited as an example of splenic removal of a portion of individual cell membrane and content without destruction of cellular integrity. On anatomical grounds, Weiss and Tavassoli visualize a progressive fragmentation of aged erythrocytes in the course of repeated splenic passage (29). Interpretation of the $\mathrm{MCHC}$ change is more difficult. This present study implies that the processes of hemoglobin and cell water loss are unequal and result in an apparent gain in cell water as the cell volume decreased. At least two explanatory theories might be advanced. First, there may be a specific change in membrane permeability to water and electrolyte associated with the aging process, resulting in a gradual fall in hemoglobin concentration within the cell, irrespective of the loss of cell membrane and hemoglobin. A second theory would connect the two processes. It could be postulated that the concentration of hemoglobin near the red cell membrane increases with age because of water and electrolyte loss 
through a leaky membrane or denaturation of hemoglobin. If the latter were true, the splenic removal of a piece of membrane and a small portion of hemoglobin content would have to result in a decrease in hemoglobin concentration, since more hemoglobin than water would be lost in this fragment. This theory is somewhat more attractive for it not only explains the results of this study but also provides a potential reason for the initiation of splenic remodeling; that is, an increase in cell rigidity secondary to the higher concentration of normal denatured hemoglobin just inside the membrane.

\section{ACKNOWLEDGMENTS}

The technical assistance of Lilian Frei, Sylvia Schibli, and Caryl Campbell is greatly appreciated.

This investigation was supported by the Schweizerischer Nationalfonds zur Förderung der wissenschaftlichen Forschung, Grants 5068 and 3.89.69; National Institutes of Health, Grant AM137132; and American Heart Association, Grant 67-680.

\section{REFERENCES}

1. Chalfin, D. 1956. Differences between young and mature rabbit erythrocytes. J. Cell. Comp. Physiol. 47: 215.

2. Hoffman, J. F. 1958. On the relationship of certain erythrocyte characteristics to their physiological age. J. Cell. Comp. Physiol. 51: 415.

3. Prankerd, T. A. J. 1958. The aging of red cells. J. Physiol (London). 143: 325.

4. Garby, L., and M. Hjelm. 1963. Ultracentrifugal fractionation of human erythrocytes with respect to cell age. Blut. 9: 284.

5. Leif, R. C., and J. Vinograd. 1964. The distribution of buoyant density of human erythrocytes in bovine albumin solutions. Proc. Nat. Acad. Sci. U. S. A. 51: 520.

6. Danon, D., and V. Marikovsky. 1964. Determination of density distribution of red cell population. J. Lab. Clin. Med. 64: 668

7. O'Connell, D. J., C. J. Caruso, and M. D. Sass. 1965. Separation of erythrocytes of different ages. Clin. Chem. 11: 771.

8. Wilton, A. 1966. An attempt to separate erythrocytes according to age by a new type of centrifuge. Acta. Haematol. 35: 163.

9. Bishop, C., and T. C. Prentice. 1966. Separation of rabbit red cells by density in a bovine serum albumin gradient and correlation of red cell density with cell age after in vivo labeling with ${ }^{50} \mathrm{Fe}$. J. Cell Physiol. 67: 197.

10. Piomelli, S., G. Lurinsky, and L. R. Wasserman. 1967. The mechanism of red cell aging. I. Relationship between cell age and specific gravity evaluated by ultracentrifugation in a discontinuous density gradient. $J$. $L a b$. Clin. Med. 69: 659.
11. Coopersmith, A., and M. Ingram. 1968. Red cell volumes and erythropoiesis. I. Age: density: volume relationship of normocytes. Amer. J. Physiol. 215: 1276.

12. Fornaini, G. 1967. Biochemical modifications during the life span of the erythrocyte. Ital. J. Biochem. 16: 257.

13. Chapman, R. G., and L. Schaumburg. 1967. Glycolysis and glycolytic enzyme activity of aging red cells in man. Changes in hexokinase, aldolase, glyceraldehyde-3-phosphate dehydrogenase, pyruvate kynase and glutamic-oxalacetic transaminase. Brit. J. Haematol. 13: 665.

14. Allison, A. C., and G. P. Burn. 1955. Enzyme activity as a function of age in the human erythrocyte. Brit. $J$. Haematol. 1: 291.

15. Löhr, G. W., and H. D. Waller. 1961. Zur Biochemie der Erythrocytenalterung. Folia Haematol. (Leipzig). 78: 385 .

16. Marks, P. A., and A. B. Johnson. 1958. Relationship between the age of human erythrocytes and their osmotic resistance: a basis for separating young and old erythrocytes. J. Clin. Invest. 37: 1542.

17. Van Dilla, M. A., and J. F. Spalding. 1967. Erythrocyte volume distribution during recovery from bone marrow arrest. Nature (London). 213: 708.

18. Syllm-Rapoport, I., and D. Schmidt. 1961. Ueber die in vivo-Alterung transfundierter Erythrocyten bei einem Fall von kongenitaler Erythrogenesis imperfecta (Diamond-Blackfan). Acta. Biol. Med. Ger. 7: 452.

19. Reissmann, K. R., and K. Ito. 1966. Selective eradication of erythropoiesis by actinomycin $D$ as the result of interference with hormonally controlled effector pathway of cell differentiation. Blood. 28: 201.

20. Ganzoni, A., R. S. Hillman, and C. A. Finch. 1969. Maturation of the macroreticulocyte. Brit. J. Haematol. 16: 119.

21. Brecher, G., E. F. Jakobek, M. A. Schneiderman, G. Z. Williams, and P. J. Schmidt. 1962. Size distribution of erythrocytes. Ann. N. Y. Acad. Sci. 99: 242.

22. Winter, H., and R. P. Sheard. 1965. The skewness of volume distribution curves of erythrocytes. Aust. J. Exp. Biol. Med. Sci. 43: 687 .

23. Shank, B. B., R. B. Adams, K. D. Steidley, and J. R. Murphy. 1969. A physical explanation of the bimodal distribution obtained by electronic sizing of erythrocytes. J. Lab. Clin. Med. 74: 630 .

24. Belcher, E. H., and E. B. Harriss. 1959. Studies of red cell life span in the rat. J. Physiol. (London). 146: 217.

25. Berlin, N. I., T. A. Waldmann, and S. M. Weissman. 1959. Life span of red blood cell. Physiol. Rev. 39: 577.

26. Sondhaus, C. A. 1958. The hemoglobin content of single erythrocytes in cell aging and hemopoietic disturbance. Univ. Calif. UCRL-8203 Biol. Med.

27. Weed, R. I., and C. F. Reed. 1966. Membrane aiterations leading to red cell destruction. Amer. J. Med. 41: 681.

28. Ronbinson, S. H., and M. Tsong. 1970. Hemolysis of "stress" reticulocytes: a source of erythropoietic bilirubin formation. J. Clin. Invest. 49: 1025.

29. Weiss, L., and M. Tavassoli. 1970. Anatomical hazards to the passage of erythrocytes through the spleen. Semin. Hematol. 7: 372. 